\title{
Primary Antiphospholipid syndrome presenting with acute ST elevated MI with normal coronaries.
}

\author{
LOHANI MD. TAJUL ISLAM, ABDUL WADUD CHOWDHURY, AKM FAZLUR RAHMAN, SARJANA SULTANA, \\ DMM F OSMANY, MD NAZMUL HASAN
}

Department of Cardiology, Bangabandhu Sheikh Mujib Medical University, Dhaka, Bangladesh.

Address for Correspondence: Dr Lohani Md. Tajul Islam, Medical Officer, Department of Cardiology, Bangabandhu Sheikh Mujib Medical University, Dhaka, Bangladesh. Email: lohanibsmmu@yahoo.com

\begin{abstract}
:
Myocardial infarction (MI) under the age of 40 years accounts for around $3 \%$ of cases of coronary artery disease. Coronary artery atherosclerosis is less commonly the underlying aetiology in this age group and more comprehensive investigation of the cause is required. Antiphospholipid syndrome is a rare cause for MI which can be found younger age group. Here, We report a22 years young patients with MI who had normal coronary arteries on coronary angiogram that proved to have primary APS.
\end{abstract}

\section{Introduction:}

Antiphospholipid syndrome (APS) is the association of persisting antiphospholipid (aPL) antibodies with a thrombotic event ${ }^{4}$.Unlike the congenital thrombophilias that mainly predispose to venous thrombosis, aPL antibodies can cause thrombosis in any vascular bed, including the coronary artery circulation ${ }^{5}$.It is crucial not to miss this diagnosis as the patients are more likely to have recurrent thrombotic episodes ${ }^{3,6}$ and the recommended treatment is high-dose oral anticoagulation; standard secondary prevention of atherosclerosis with antiplatelet agents and risk factor modification are likely to be ineffective.

\section{Case Report:}

A 22-year-old non-smoker, garments worker was admitted with two hours history of severe central chest pain, compressive in nature associated with profuse sweating and vomiting without any radiation of pain. He was non diabetic, normotensive and no family history of coronary artery disease or premature cardiovascular death. Initial 12 lead ECG revealed for an ST elevation MI in the anterior surface.Cardiac biomarkers,CK MB was $120 \mathrm{IU} / \mathrm{dl}$ and Troponin I was $15.20 \mathrm{ng} / \mathrm{L}$. He had normal coronary arteries at angiography with a type IV left anterior descending (LAD) artery. There was antero-septal hypokinesia with a visible apical thrombus in left ventricle with an ejection fraction of $40 \%$ on echocardiography. IgG anticardiolipin antibodies were raised on two occasions and he had a positive lupus anticoagulant.His anti ${ }^{2} 2$ glycoprotein antibody was also positive .He was treated with initial thrombolysis and now on warfarin along with other anti ischemic medications.

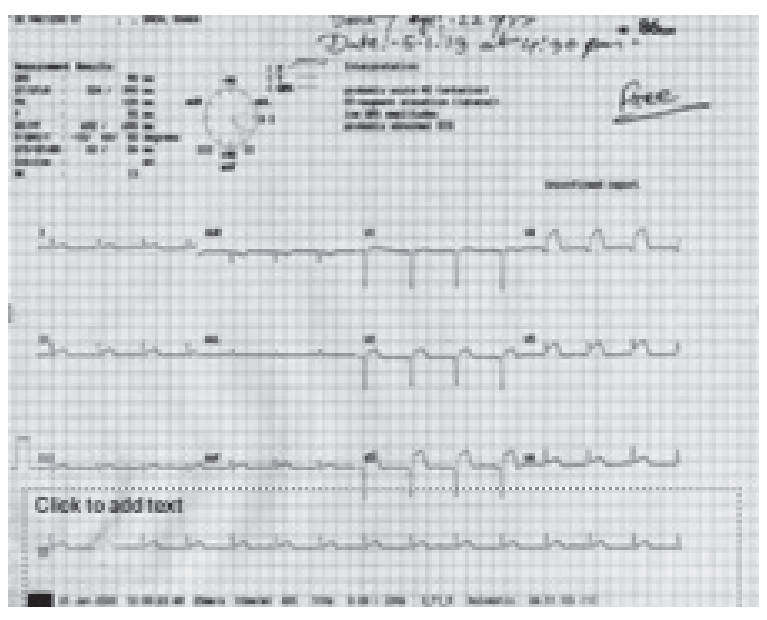

Fig.-1: 12 lead ECG showing ST elevation in anterior leads.

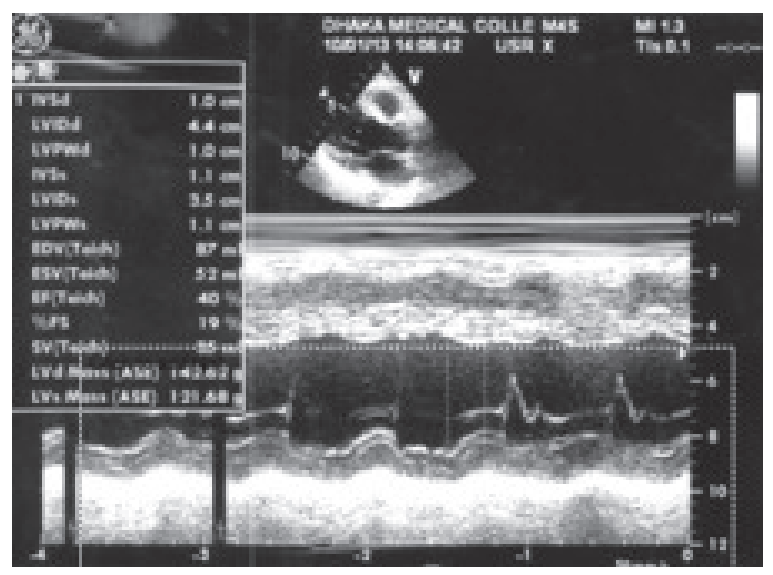

Fig.-2: Trans Thoracic Echocardiogram showing septal hypokinesia with moderate LV systolic function. 


\section{Discussion:}

Diagnosing APS is not always easy. It requires a combination of clinical findings (vascular thrombosis or pregnancy morbidity) and laboratory criteria. Current laboratory criteria for APS require two positive tests of either lupus anticoagulant and/or anticardiolipin antibodies at least 12 weeks apart ${ }^{7}$. Recently, anti- ${ }^{2}-2$ glycoprotein-1 antibodies have been added to the diagnostic criteria by an international group of experts ${ }^{4}$. It is difficult to test for and interpret the results of screens for aPL antibodies as there is heterogeneity of aPL antibodies between individuals and there is a lack of national and international standardisation of the assays.

There are a number of assays to diagnose lupus anticoagulant. We have used the dilute Russell viper venom and activated partial thromboplastin time assays. The principle of the lupus anticoagulant assays is that phospholipid is required for coagulation to proceed, and so in the presence of an aPL antibody, the phospholipid clotting time is prolonged because of the aPL antibody binding the phospholipid. The second stage is to add excess phospholipid (usually platelet extract), which removes the aPL antibodies and shortens the clotting time ${ }^{8}$. Anticoagulation interferes with the lupus anticoagulant making the results difficult to interpret unless specific assays are used. If a patient is taking oral anticoagulation, our practice is to switch them to low molecular weight (LMW) heparin for 2 weeks and then omit the LMW heparin for $24 \mathrm{~h}$ prior to the test. Initially negative tests do not exclude aPL antibodies, and we would suggest that the test is repeated on two occasions before the diagnosis is formally excluded. It is important to perform two sets of tests separated by 12 weeks because aPL antibodies can become transiently positive, and this is not associated with thrombotic risk.

After MI, up to $15 \%$ of patients have aPL antibodies compared with around $4.4 \%$ in a control population ${ }^{1,9}$. In addition, some authors ${ }^{3,10}$ have found that aPL antibodies after MI are a risk factor for recurrent events, although these results have not been verified by others ${ }^{11,12}$. In addition, anticardiolipin antibodies in healthy men have been shown to confer a twofold increased relative risk for $\mathrm{MI}^{2}$.

There are probably three relationships between aPL antibodies and coronary artery disease: first, aPL antibodies can cause thrombosis in normal vessels; secondly, they may be associated with accelerated atherosclerosis; and lastly, in some individuals transient aPL antibodies may arise at the time of MI because of vascular injury and exposure of neoantigens. Whether an aPL antibodies can be induced in response to the tissue necrosis that occurs during MI remains uncertain ${ }^{13}$.
In this patient, it is likely that the patient had thrombosis caused by primary APS. All the patients who had repeat testing had persisting aPL antibodies making the aPL antibodies unlikely to be the result of a transient phenomenon secondary to vascular injury. In contrast, aPL antibodies arising after MI in patients with significant coronary artery disease are most likely to be transient.

\section{References:}

1. Sletnes KE, Smith P, Abdelnoor M, Arnesen H, Wisloff F. Antiphospholipid antibodies after myocardial infarction and their relation to mortality, reinfarction, and non-haemorrhagic stroke. Lancet 1992; 339: 451- 3.

2. Vaarala O, Manttari M, Manninen V et al. Anti-cardiolipin antibodies and risk of myocardial infarction in a prospective cohort of middle-aged men. Circulation 1995; 91: 23-7.

3. Hamsten A, Norberg R, Bjorkholm M, de Faire U, Holm G. Antibodies to cardiolipin in young survivors of myocardial infarction: an association with recurrent cardiovascular events. Lancet 1986; 1: 113-6.

4. Miyakis $\mathrm{S}$, Lockshin MD, Atsumi $\mathrm{T}$ et al. International consensus statement on an update of the classification criteria for definite antiphospholipid syndrome (APS). J Thromb Haemost 2006; 4: 295-306.

5. Robertson B, Greaves M. Antiphospholipid syndrome: an evolving story. Blood Rev 2006; 20: 201-12.

6. Khamashta MA, Cuadrado MJ, Mujic F, Taub NA, Hunt BJ, Hughes GR. The management of thrombosis in the antiphospholipid-antibody syndrome. N Engl J Med 1995; 332: $993-7$.

7. Wilson WA, Gharavi AE, Koike T et al. International consensus statement on preliminary classification criteria for definite antiphospholipid syndrome: report of an international workshop. Arthritis Rheum 1999; 42: 1309-11.

8. Brandt JT, Triplett DA, Alving B, Scharrer I. Criteria for the diagnosis of lupus anticoagulants: an update. On behalf of the Subcommittee on Lupus Anticoagulant/Antiphospholipid Antibody of the Scientific and Standardisation Committee of the ISTH. Thromb Haemost 1995; 74: 1185-90.

9. Vaarala O. Antiphospholipid antibodies and myocardial infarction. Lupus 1998; 7 (Suppl. 2): S132-4.

10. Bili A, Moss AJ, Francis CW, Zareba W, Watelet LF, Sanz I. Anticardiolipin antibodies and recurrent coronary events: a prospective study of 1150 patients. Thrombogenic Factors, and Recurrent Coronary Events Investigators. Circulation 2000; 102: 1258-63.

11. De Caterina R, d'Ascanio A, Mazzone A et al. Prevalence of anticardiolipin antibodies in coronary artery disease. Am J Cardiol 1990; 65: 922-3.

12. Phadke KV, Phillips RA, Clarke DT, Jones M, Naish P, Carson P. Anticardiolipin antibodies in ischaemic heart disease: marker or myth? Br Heart J 1993; 69: 391-4.

13. Vaarala O. Antiphospholipid antibodies and atherosclerosis. Lupus 1996; 5: 442-7. 